\title{
Problems and Immediate Outcome of Infants of Diabetic Mothers
}

\author{
CB MAHMOOD ${ }^{\mathrm{a}}$, MI KAYES ${ }^{\mathrm{b}}$
}

Summary:

Objective:The present study was undertaken to evaluate the problems and immediate outcome of infants of diabetic mothers(IDMs) in early neonatal period and to compare the results between infants of gestational and pregestational diabetic mothers.

Design: A hospital based prospective study. Setting: The study was done in Chittagong Medical College Hospital, a tertiary hospital in Chittagong city. Method: Within one hour of delivery 52 infants of diabetic [pregastational \& gestational] mothers consecutively admitted were enrolled in the study. Study period was January 2002 to August 2002.

Results: Total number of IDMs were 52.Among them 31 were gestational and 21 were of pregestational diabetic mothers.

Significant number $82.6 \%$ of IDMs were delivered by caesarean section. The mean birth weight of IDMs was significantly high(3212 $\pm 563 \mathrm{~g}), 21 \%$ of IDMs had birth weight>4000 g. Total $23 \%$ of the IDMs developed perinatal asphyxia. .The $23 \%$ of IDMs developed hypoglycaemia.The incidence of hypoglycaemia was higher in infants of pregestational diabetic mothers as compared to that of gestational diabetic mothers $(38.09 \%$ and $12.9 \%$ respectively), the difference was statistically significant $(P<0.05)$.In majority (66\%) of IDMs cases hypoglycaemia was symptomatic. Significant number

\section{Introduction:}

Diabetes mellitus is characterized by hyperglycaemia, disturbance of carbohydrate, fat and protein metabolism that are associated with absolute or relative deficiencies in insulin action and/or insulin

a. Professor Dr. Chowdhury B. Mahmood, FCPS(Ped.), DME(UK) Professor \& Head, Department of Child Health, Chittagong Medical College \& Hospital, Chittagong.

b. Dr.Mohammad Imrul Kayes, FCPS(Ped), Research assistant, Department of Child Health, Chittagong Medical College \& Hospital, Chittagong.

Address of correspondence: Dr.Mohammad Imrul Kayes, FCPS(Ped), Research assistant, Department of Child Health, Chittagong Medical College \& Hospital, Chittagong, Mobile:01819177457

Received: 10 December, 2007

Accepted: 8 March, 2008
(19.2\%) of IDMs had hypocalcaemia. The incidence of polycythaemia was higher in infants of gestatational diabetic mothers(GDMs) as compared to infants of pregestational diabetic mothers $(25.8 \%$ and $9.5 \%$ respectively), difference was statistically significant $(P<0.001)$. 3(5.7\%) out of 52 IDMs had congenital malformation (each one in number polydactyly, cleft palate \& preauricular skin tag). Total death was 3(5.7\%) all of them died within 72 hours of birth. Causes of death 1 each number: perinatal asphyxia, respiratory distress syndrome and meconium aspiration syndrome. 11 IDM was macrosomic, among them 1 had birth injury( Erb's palsy), hypoglycaemia and meconium aspiration syndrome and expired within first 24 hours of life.

Conclusion:Among the important problems the present study revealed perinatal asphyxia, hypoglycaemia, hypocalcaemia, polycythaemia top the list. These babies should be delivered at hospitals where special neonatal care available for management of high risks babies to reduce the morbidity and mortality. Screening for GDMs should be performed in all pregnant women. All diabetic women should have planned pregnancy and proper antenatal care in order to maintain strict glycaemic control, to have a satisfactory outcome in infants of diabetic mothers.

(J Bangladesh Coll Phys Surg 2008; 26: 67-72)

secretion ${ }^{1}$. Diabetes mellitus is the commonest endocrine disorder during pregnancy. In fact many prediabetics and potential diabetics may show chemical evidences of diabetes mellitus during the course of metabolic stress of pregnancy. Gestational diabetes where in glucose homeostasis returns back to nomal after delivery, also increases various risk to the fetus and newborn. The duration and severity of maternal diabetes and quality of its control during pregnancy determine the outcome of the offspring ${ }^{2}$

Diabetes mellitus is prevalent among $2.1 \%$ people of Bangladesh ${ }^{3}$.Gestational diabetes mellitus (GDM) develops among $6.7 \%$ of all pregnancies in our population ${ }^{4}$. In western world 2 to $3 \%$ of all pregnancies are currently being diagnosed as $\mathrm{GDM}^{5}$. 
Infant of diabetic mothers have a $47 \%$ risk of significant hypoglycaemia, $22 \%$ risk of hypocalcaemia, $19 \%$ risk of hyperbilirubinemia, $34 \%$ risk of polycythaemia, $6-9 \%$ incidence of major congenital anomalies( congenital heart disease, central nervous system \& vertebral anomalies $)^{6}, 4 \%$ risk of respiratory distress syndrome, $28 \%$ risk of macrosomia \& cardiomegaly (30\%).

Among the various metabolic errors these infants suffer, hypoglycaemia is the commonest and most dangereous 7 .Infants of diabetic mothers have hyperinsulinism at birth due to increased placental transfer of glucose and other nutrients stimulating hyperplasia of islets of Langerhans in the fetus and increased insulin secretion, raised amount of Cpeptide and free insulin in cord blood. Once the maternal supply of glucose is cut-off by clamping the cord, the excess insulin circulating in the baby's system quickly rids the plasma of the remaining glucose and so blood glucose level may drop precipitously and alarmingly during the first few hours of life ${ }^{8}$. Hypoglycaemia is defined as a blood glucose level less then $2.6 \mathrm{mmol} / \mathrm{L}$. Symptoms of hypoglycaemia, are non specific, such as lethargy, apathy, limpness, apnea, cyanosis, weak or high pitched cry, poor feeding ,vomiting, tremors, jitteriness , irritability,seizures, coma ${ }^{9}$. Neonetal hypocalcaemia may be due to hypoparathyroidism, abnormal vitamin D metabolism and hyperphosphataemia. Neonatal hypocalcaemia is defined as total serum calcium concentration of less than $7 \mathrm{mg} / \mathrm{dl}$ and an ionized calcium conc. of less than $4 \mathrm{mg} / \mathrm{dl}^{10}$. Polycythaemia (haematocrit of more than 0.651 ) occurs in 30 to $60 \%$ of IDMs causing the neonatal hyperviscosity syndrome. The main cause of polycythaemia is chronic intrauterine hypoxaemia, which occurs as consequence of fetal hyperinsulinism and hyperglycaemia. ${ }^{11}$.

Macrosomia (birth weight $>4000$ g) may be associated with increased incidence of primary caesarean section or obstetric trauma such as fractured clavicle, Erb's palsy or phrenic nerve palsy due to shoulder dystocia ${ }^{7,9}$.

Hypertropic cardiomyopathy with asymmetric septal hypertrophy has been extensively documented ${ }^{10}$.The babies may also develop small left colon syndrome, a transient delay in the development of left side of colon. ${ }^{4,5}$.Despite improvement in diabetic care, the perinatal mortality still remains four times high than in nondiabetic women. Predominant causes of mortality are congenital anomaly, birth trauma, respiratory distress syndrome, prematurity and unexplained still birth ${ }^{12}$.

Although in developed countries there has been significant improvement in the outcome of diabetic pregnancies largely due to better metabolic control before and during pregnancy and vigorous neonatal care, the management in our country still poses a major challenge.

Aims of this study were to find out problems of IDM during early neonatal period that threaten baby's life and with appropriate management to determine immediate outcome in hospitalized IDM. The study was designed to evaluate the problems and immediate outcome of infants of diabetic mothers in early neonatal period and to compare the results between infants of gestational and pregestational diabetic mothers in neonatal unit of Chittagong Medical College Hospital,Chittagong.

\section{Materials and Method:}

This hospital based prospective study was done in neonatal unit of Chittagong Medical College Hospital in collaboration with Department of Obstetrics and Gynecology of this hospital. Within one hour of delivery 52 infants of diabetic [pregestational \& gestational] mothers consecutively admitted for observation and further management where enrolled in the study. Exclusion criterion was infants of diabetic mothers were admitted as referred case from other hospitals. Study period was January 2002 to August 2002.

After taking the verbal consent from the attendant, the relevant information from the history, physical examination and investigation findings were recorded in a purposely prepared questionnaire. Investigations routinely underwent were capillary blood glucose at 0 (cord blood), 2, 4, 6, 12,24,48 and 72 hours of age by using glucostix. Peripheral blood glucose was collected with single puncture non-squeezing procedure by trained technician and level measured by Glucose oxidase method in auto analyzer at 6 , $12,24,48,72$ hours of age and whenever any 
symptoms suggestive of hypoglycaemia developed. The glucostix(capillary blood glucose) was used for screening purpose and for prompt diagnosis and management of hypoglycaemia and estimation of peripheral venous blood glucose level was done for further confirmation of diagnosis. Serum calcium level were measured routinely at $6,24,48$ hours of age and later if the baby remains hypocalcaemic or symptomatic. Hematocrit at 1 hour \& 24 hour of age was done routinely. Blood samples collected in each time in all cases by trained technician, results were measured by autoanalyzar and interpreted by expert person. Among other investigations: platelets count, CXR PA view, plain $\mathrm{X}$ ray of lumbosacral spine, $\mathrm{Hb} \%$, TC, DC, blood culture, ECG, echocardiography etc were done as indicated by clinical parameters, not done routinely in all cases as study population were admitted within one hour of delivery for management and further observation whether any problem developed. Results were analyzed by analyzing software SPSS.

\section{Results:}

Total number of IDMs were 52.Among them $31(59.6 \%)$ were gestational diabetic mothers and $21(40.3 \%)$ were of pregestational diabetic mothers (Table-I).

$92.3 \%$ of the IDMs were term as compared to $7.6 \%$ preterm delivery and majority of the $\operatorname{IDMs}(82.6 \%)$ were delivered by caesarean section as compared to $17.3 \%$ normal delivery (Table-II).

Macrosomia was found in $21.1 \%$ ( Table-III).

$12(23 \%)$ out of 52 IDMs developed perinatal asphyxia. $25.8 \%$ of IGDMs developed perinatal asphyxia in comparison to $19 \%$ of IPGDMs, although the difference is not significant statistically $(\mathrm{P}>0.50)$ as shown in Table-IV. Table-V shows $23 \%$ of IDMs developed hypoglycaemia. Among the 12 infants (23\%) having hypoglycaemia, only 8 were symptomatic. Lethergy \& jitteriness was most commonly observed. Only 2 newborns developed seizure. The occurrence of hypoglycaemia was higher in infants of pregestational diabetic mothers as compared to that of GDM mothers $38.09 \%$ and $12.9 \%$ respectively) the difference was statistically significant $(\mathrm{p}<0.05)$ as in Table-VI. $10(19.2 \%)$ of the IDMs developed hypocalcaemia.16.1\% \& 23.8\% infants of gestational \& pregestational diabetic mothers had hypocalcaemia respectively and the difference was not statistically significant $(\mathrm{P}>0.50)$. Out of the 10 , four had symptoms, mainly jitteriness (Table-VII).

In this study ,25.8\% and $9.5 \%$ of infants of gestational and pregestational diabetic mothers developed polycythaemia respectively and the difference was statistically significant $(\mathrm{P}<0.001)$ shown in Table-VIII.

In the present study, 3(5.7\%) out of 52 IDMs had congenital malformation (each one in number: polydactyly, cleft palate \& preauricular skin tag).In the study undertaken, $2(3.8 \%)$ of IDMs developed RDS (respiratory distress syndrome), one of which expired and another one survived. Out of 52 IDMs one developed meconium aspiration syndrome also had birth injury (Erb's palsy) and hypoglycaemia and expired within 24 hours of birth. Another IDM had severe perinatal asphyxia and expired (Table IX).

Total survival of IDM was 49(94.2\%) and discharged within 7 days of admission.

\section{Table-I}

Distribution of neonates according to type of maternal diabetes $(n=52)$

\begin{tabular}{lcc} 
Group & No. of cases & Percentage \\
\hline IGDMs & 31 & 59.61 \\
IPGDMs & 21 & 40.38 \\
IDMs (n=52) & & \\
\hline
\end{tabular}

IGDMs = Infants of gestational diabetic mothers IPGDMs $=$ Infants of pregestational diabetic mothers IDMs = Infants of diabetic mothers

Table-II

Frequency of gestational age \& mode of delivery in $\operatorname{IDMs}(n=52)$.

\begin{tabular}{lcc} 
Features & No. & $\%$ \\
\hline Gestational age: & & \\
Term & 48 & 92.3 \\
Preterm & 04 & 7.6 \\
Mode of delivery: & & \\
Normal & 09 & 17.3 \\
Caesarian & 43 & 82.6 \\
\hline
\end{tabular}


Table-III

Distribution of IDMs according to birth weight $(n=52)$

\begin{tabular}{lcc} 
Birth weight(grams) & No. of cases & Percentage \\
\hline $1500-2499$ & 04 & 7.6 \\
$2500-2999$ & 06 & 11.5 \\
$3000-3499$ & 15 & 28.8 \\
$3500-4000$ & 16 & 30.7 \\
$>4000$ & & \\
& 11 & 21.1 \\
\hline
\end{tabular}

Mean $3212 \pm 563$

Table-IV

Frequency of perinatal asphyxia in IGDMs \& IPGDMs.

\begin{tabular}{|c|c|c|c|c|c|}
\hline \multirow[b]{2}{*}{ Group } & \multicolumn{2}{|c|}{$\begin{array}{c}\text { Perinatal } \\
\text { sphyxia } \\
\text { Present }\end{array}$} & \multicolumn{2}{|c|}{$\begin{array}{c}\text { Perinatal } \\
\text { asphyxia } \\
\text { absent }\end{array}$} & \multirow[b]{2}{*}{$\mathrm{P}$ value } \\
\hline & No & $\%$ & No & $\%$ & \\
\hline IGDMs $(n=31)$ & 8 & 25.80 & 23 & 74.19 & $\mathrm{P}>0.50$ \\
\hline IPGDMs $(\mathrm{n}=21)$ & 4 & 19.04 & 17 & 80.95 & \\
\hline IDMs $(\mathrm{n}=52)$ & 12 & 23.07 & 40 & 76.92 & \\
\hline
\end{tabular}

Table -V

\begin{tabular}{|c|c|c|c|c|c|c|}
\hline \multicolumn{7}{|c|}{$\begin{array}{c}\text { Frequency of hypoglycaemia in IDM: } \\
\text { Number } 12(23 \%)\end{array}$} \\
\hline & \multicolumn{2}{|c|}{$\begin{array}{c}\text { IGDMs } \\
\mathrm{n}=31\end{array}$} & \multicolumn{2}{|c|}{$\begin{array}{c}\text { IPGDMs } \\
\mathrm{n}=21\end{array}$} & \multicolumn{2}{|c|}{$\begin{array}{c}\text { IDMs } \\
\text { (Total, } \mathrm{n}=52)\end{array}$} \\
\hline & No & $\%$ & No & $\%$ & $\overline{\text { No }}$ & $\%$ \\
\hline Symptomatic & 3 & 9.6 & 5 & 23.8 & 8 & 15.3 \\
\hline Asymptomatic & 1 & 3.2 & 8 & 38.0 & 12 & 23.0 \\
\hline Total & 4 & 12.9 & & & & \\
\hline
\end{tabular}

\section{Table -VI}

Frequency of hypoglycaemia in IGDMs \& IPGDMs.

Hypoglycaemia Hypoglycaemia

$$
\text { Present absent }
$$

\begin{tabular}{lccccc} 
Group & No & $\%$ & No & $\%$ & $\mathrm{P}$ value \\
\hline IGDMs $\mathrm{n}=31$ & 4 & 12.90 & 27 & 87.09 & $\mathrm{P}>0.50$ \\
IPGDMs $\mathrm{n}=21$ & & & 13 & 61.90 & \\
IDMs (total) $\mathrm{n}=52$ & 8 & 38.09 & 40 & 76.92 & \\
& 12 & 23.07 & & & \\
\hline
\end{tabular}

Table -VII

Frequency of hypocalcaemia in IGDMs \& IPGDMs.

Hypocalcaemia Hypocalcaemia

\begin{tabular}{lcccccc} 
& \multicolumn{2}{c}{ Present } & & \multicolumn{2}{c}{ absent } & \\
\cline { 2 - 3 } Group & No & $\%$ & & No & $\%$ & P value \\
\hline IGDMs n=31 & 5 & 16.12 & & 26 & 83.87 & P $>0.50$ \\
IPGDMs n=21 & & & & 16 & 76.19 & \\
IDMs (total) $n=52$ & 5 & 23.80 & & 42 & 80.76 & \\
& 10 & 19.23 & & & \\
\hline
\end{tabular}

Table -VIII

Frequency of polycythaemia in IDMs.

\begin{tabular}{lcccccc} 
& \multicolumn{2}{c}{$\begin{array}{c}\text { Polycythaemia } \\
\text { Present }\end{array}$} & & \multicolumn{2}{c}{$\begin{array}{c}\text { Polycythaemia } \\
\text { absent }\end{array}$} & \\
\cline { 2 - 3 } Group & No & $\%$ & & No & $\%$ & P value \\
\hline IGDMs n=31 & 8 & 25.80 & & 23 & 74.19 & $\mathrm{P}>0.50$ \\
IPGDMs n=21 & 2 & 9.52 & & 19 & 90.47 & \\
IDMs (total) $\mathrm{n}=52$ & 10 & 19.23 & & 42 & 80.76 & \\
\hline
\end{tabular}

Table - IX

\begin{tabular}{|c|c|c|c|c|}
\hline \multicolumn{2}{|l|}{ Problems } & $\begin{array}{c}\text { Total } \\
\text { survival }=49 \\
\text { Number } \% \\
\end{array}$ & $\begin{array}{c}\text { Total } \\
\text { death }=3 \\
\text { Number \% }\end{array}$ & $\begin{array}{c}\text { Total } \\
\text { cases } \mathrm{n}=52 \\
\text { Number } \% \\
\end{array}$ \\
\hline \multirow{5}{*}{$\begin{array}{l}\text { Birth weight } \\
\text { (gm) }\end{array}$} & $1500-2499$ & $03(6.1)$ & $01(33.3)$ & $04(7.6)$ \\
\hline & 2500-2999 & $05(10.2)$ & $01(33.3)$ & $06(11.5)$ \\
\hline & $3000-3499$ & $15(30.6)$ & - & $15(28.8)$ \\
\hline & $3500-4000$ & $15(30.6)$ & $\longrightarrow$ & $16(30.7)$ \\
\hline & $>4000$ & $11(22.4)$ & $01(33.3)$ & $11(21.1)$ \\
\hline \multirow{2}{*}{$\begin{array}{l}\text { Perinatal } \\
\text { asphyxia }\end{array}$} & Yes & $11(22.4)$ & $01(33.3)$ & $12(23.0)$ \\
\hline & No & $38(77.5)$ & $02(66.6)$ & $40(76.9)$ \\
\hline \multirow[t]{2}{*}{ Hypoglycaemia } & Yes & $10(20.4)$ & $02(66.6)$ & $12(23.0)$ \\
\hline & No & $39(79.5)$ & $01(33.3)$ & $40(76.9)$ \\
\hline \multirow[t]{2}{*}{ Hypocalcaemia } & Yes & $10(20.4)$ & $\longrightarrow$ & $10(19.2)$ \\
\hline & No & $39(79.5)$ & $03(100.0)$ & $42(80.7)$ \\
\hline \multirow[t]{2}{*}{ Polycythaemia } & Yes & $10(20.4)$ & $\longrightarrow$ & $10(19.2)$ \\
\hline & No & $39(79.5)$ & $03(100.0)$ & $42(80.7)$ \\
\hline \multirow{2}{*}{$\begin{array}{l}\text { Congenital } \\
\text { malformations }\end{array}$} & Yes & $03(6.1)$ & - & $03(5.7)$ \\
\hline & No & $46(93.8)$ & $03(100.0)$ & $49(94.2)$ \\
\hline \multirow[t]{2}{*}{ Birth injuries } & Yes & $01(2.0)$ & $01(33.3)$ & $02(3.8)$ \\
\hline & No & $48(97.9)$ & $02(66.6)$ & $50(96.1)$ \\
\hline \multirow{2}{*}{$\begin{array}{l}\text { Respiratory distress } \\
\text { syndrome }\end{array}$} & Yes & $01(2.0)$ & 01(33.3) & $02(3.8)$ \\
\hline & No & 48(97.9) & $02(66.6)$ & $50(96.1)$ \\
\hline \multirow{2}{*}{$\begin{array}{l}\text { Meconium } \\
\text { aspiration } \\
\text { syndrome }\end{array}$} & Yes & $00(0)$ & $01(33.3)$ & 01(1.9) \\
\hline & No & $49(100)$ & $02(66.6)$ & $51(98.0)$ \\
\hline
\end{tabular}




\section{Discussion:}

Diabetes mellitus is prevalent among $2.1 \%$ people of Bangladesh. ${ }^{13}$ Among them a significant number are female. GDM (gestational diabetes mellitus) develops among $6.7 \%$ of all pregnancies in our population. ${ }^{14}$. In western world 2 to $3 \%$ of all pregnancies are currently being diagnosed as GDM ${ }^{5}$. In this study, the total number of IDMs was 52 . Among them 31 were gestational diabetic mothers and 21 were pregestational diabetic mothers. Begum $\mathrm{A}^{15}$ in a study of 105 newborns reported that $44.4 \%$ of diabetic mothers had GDM and remaining were pregestational. Begum $\mathrm{N}^{16}$ in her study found that among 112 diabetic mothers $58.9 \%$ had GDM and $41 \%$ had pregestational diabetes mellitus. $93 \%$ of the IDMs were term as compared to $7.6 \%$ preterm delivery in the present study. IDMs may need to be delivered prematurely due to maternal or fetal problems. Ranade et al. ${ }^{17}$ reported $36 \%$ of the IDMs to be preterm. Overall, $26 \%$ of the diabetic women deliver before 37 weeks gestation, compared with $10 \%$ in general population. ${ }^{12}$. In this study majority of the IDMs $(82.6 \%)$ were delivered by caesarean section as compared to $17.3 \%$ normal delivery. Mohsin $\mathrm{F}^{18}$ in her study found that the rate of caesarean section (80\%) in IDMs. The mean birth weight was significantly high $3212 \pm 563 \mathrm{~g}$ in the present study. Mohsin $\mathrm{F}^{18}$ and Begum $\mathrm{N}^{16}$ in their study found the mean birth weight of IDMs to be $3038 \pm 69 \mathrm{~g}$ and $2970 \pm 636 \mathrm{~g}$ respectively. Macrosomia, that is, a birth weight above the $90^{\text {th }}$ percentile for gestational age or weight $>4000 \mathrm{~g}$. was found in $22.4 \%$ in the present study. The incidence of macrosomia in IDMs has been reported to be in the range of 20 to $32 \%$ by Gabee et a $1^{19}$ and Elliot et $\mathrm{al}^{20}$. Perinatal asphyxia that occurs in IDMs is perhaps a result of multiple factors: maternal hypertension with resultant reduction of placental blood flow, premature labour ,fetal macrosomia and maternal hyperglycaemia within 6 to 8 hours preceding delivery, which supposedly reduces placental blood flow $^{21}$.In the study undertaken, $12(23 \%)$ out of 52 IDMs developed perinatal asphyxia. Mohsin $\mathrm{F}^{18}$ and Begum N 16 reported the incidence of perinatal asphyxia $12 \%$ and $20.53 \%$ respectively. In the present study, $25 \%$ of IGDMs developed perinatal asphyxia in comparison to $19 \%$ of IPGDMs, that was not significant $(\mathrm{P}>0.05)$. Out of 12 cases, one was severely asphyxiated and expired few hours after birth.
Among the different metabolic errors these infants suffer, hypoglycaemia is commonest and most dangerous. In this study, 12 infants $(23 \%)$ having hypoglycaemia, only 8 were symptomatic. Lethergy $\&$ jitteriness was most commonly observed. Only 2 newborns developed seizure. Ranade et al ${ }^{17}$, Hossain et $\mathrm{al}^{22}$ and Mountain ${ }^{8}$ reported the incidence to be $50 \%, 52.8 \%$ and $55.2 \%$ respectively. The occurrence of hypoglycaemia was higher in infants of pregestational diabetic mothers as compared to that of GDM mothers $38.09 \%$ and $12.9 \%$ respectively) the difference was statistically significant $(\mathrm{p}<0.05)$ in this study. $61 \%$ IPGDMs had hypoglycaemia in contrast to $44.2 \%$ in IGDMs as reported by Mountain ${ }^{8}$. Hypocalcaemia is one of the important metabolic errors the IDMs suffer, probably due to functional hypoparathyroidism ${ }^{23}$.In this study, $10(19.2 \%)$ of the IDMs developed hypocalcaemia. $16 \%$ \& $23 \%$ infants of gestational \& pregestational diabetic mothers developed hypocalcaemia respectively and the difference was not statistically significant $(\mathrm{P}>0.50)$.Out of the 10 , four had symptoms, mainly jitteriness. Marchant et $\mathrm{al}^{24}$, Ranade et $\mathrm{al}^{17}$, Deorari et $\mathrm{al}^{25}$, and Mountain ${ }^{8}$ reported the incidence of hypocalcaemia to be $60 \%, 14 \%, 13 \%$ and $25-50 \%$ respectively. In this study, total $10(19.2 \%)$ of IDMs developed polycythaemia, one case was symptomatic and needed partial exchange transfusion. Mohsin $\mathrm{F}^{18}$ reported incidence of polycythaemia $29 \%$ in her study. $25.8 \%$ and $9.5 \%$ of infants of gestational and pregestational diabetic mothers developed polycythaemia respectively and the difference was statistically significant $(\mathrm{P}<0.001)$. In the present study, congenital malformation was noticed in 3 (5.7\%) IDMs (each one in number: polydactyly,cleft palate \& preauricular skin tag). Congenital malformations have been reported to be 2-4 times as common in the offspring of diabetic mothers as compared to non-diabetic mothers ${ }^{5,12,26}$. Begum $\mathrm{N}^{16}$ in her study shown the frequency of congenital malformation in IDMs was $10.7 \%$.In the study undertaken, $2(3.8 \%)$ of IDMs developed RDS(respiratory distress syndrome), one of which expired and another one survived. Out of 52 IDMs one developed meconium aspiration syndrome also had birth injury (Erb's palsy) and hypoglycaemia and expired within 24 hours of birth. Another IDM had severe perinatal asphyxia and expired. Despite improvement in diabetic care, the perinatal mortality still remains four times higher than in nondiabetic 
women. Predominant causes of mortality are congenital anomaly, birth trauma, respiratory distress syndrome, prematurity and unexplained still birth ${ }^{12}$

\section{Conclusion:}

Despite the curbing of our perinatal mortality rate, the IDMs are victims of significant mortality and morbidity. Among the important problems the present study revealed perinatal asphyxia, hypoglycaemia, hypocalcaemia, polycythaemia top the list. These babies should be delivered at hospitals where special neonatal care available for management of high risks babies to reduce the morbidity and mortality. Screening for GDM should be performed in all pregnant women. All diabetic women should have planned pregnancy and proper antenatal care in order to maintain strict glycaemic control and to have a satisfactory outcome in infants of diabetic mothers.

\section{References}

1. World Health Organization. Prevention of diabetes mellitus: Report of a WHO Study group. Technical Report Series 844.Geneva: World health organization, 1994.

2. Meharban Singh, editor, Care of the newborn, 4 th ed, New Delhi, India, 1991; 70-71

3. Mahtab H, Latif ZA, Pathan MF. Diabetes mellitus: a handbook for professionals. Dhaka: Diabetic Association of Bangladesh, 1997.

4. Tofail A, Rahman H, Karim A, Kabir. Screening of gestational diabetes mellitus (abstract No. 850). Diabetologia 1997; 40 (Supl 1).

5. Kuhl C. Insulin secretion and insulin resistance in pregnancy and GDM. Diabetes 1991; 40: 18-24.

6. Cloherty JP, Maternal conditions that affect the fetus: Diabetes mellitus.In: Cloherty JP,Stark. AR,editors.Manual of neonatal care 4th edition, Philadelphia: LippincottRaven Publishers; 1998;15-19.

7. Merchant RH, Dalvi, R, Vidwans A.Infant of the diabetic mother. Indian Paediatr 1990; 27: 373-9.

8. Mountain KR. The infant of the diabetic mother. Bailliere's Clin Obstet Gynaecol 1991; 5: 413-441.

9. Cornblath,M.,et al. Disorders of Carbohydrate Metabolism in Infancy(3rd ED.).Cambridge,MA:Blackwell Scientific, 1991.

10. Rubin LP. Hypocalcemia, Hypercalcemia and Hypermagnesemia. In : Cloherty JP, Sturk A R, editors. Manual of Neonatal Care. 3rd edition.Boston ; Little, Brown and Company; 1991;437-446.

11. Lucas A, Morley R, Cole TG. Adverse outcome of moderate neonatal hypoglycaemia. British medical journal 1988; 297: $1304-8$
12. Pickup JC, Williams G, editors. Pregnancy and diabetes mellitus. In: Text book of diabetes.2nd ed. London: Blackwell Science Ltd ; 1997 ; 72 :1-28.

13. Mahtab H. Latif ZA, Pathan MF. Diabetes mellitus: a handbook for professionals.Dhaka: Diabetic Association of Bangladesh, 1997.

14. Tofail A, Rahman H, Karim A, Kabir. Screening of gestational diabetes mellitus(abstract No. 850). Diabetologia 1997; 40(Supl 1).

15. Begum AJS. Anthropometric measurement of newborn babies of diabetic and nondiabetic mothers in two selected hospital of Dhaka (dissertation). Dhaka: National Institute of Preventive and Social medicine, 1997.

16. Begum N. N. Study of congenital malformations in the newborns of diabetic mothers- A hospital based study ( dissertation) Dhaka: Institute of Postgraduate Medicine and Research, 1998.

17. Ranade AY, Marchant RH, Bajaj RT, Joshi NC. Infants of diabetic mother: an analysis of 50 cases. Indian Paediatr 1989; 26: 366-70.

18. Moshin F. Glucose and calcium profile in infants of diabetic mothers- An analysis of 100 Cases- A hospital based study (dissertation). Dhaka: BSMMU, 1999.

19. Gabbe SG, Meshman JH, Freeman RK. Management and outcome of class A diabetes mellitus. Am J Obstet Gynecol 1977; 127: 465-70.

20. Elliott JP, Garite TJ, Freman RK. Ultrasonic prediction of fetal macrosomia in diabetic patients. Obstet Gynecol 1982; 60: 159-63.

21. Miller. HC, Wilson HM, Siddique T, Khoury J, Tsang RC, Perinatal asphyxia in infants of Insulin-dependent diabetic mothers. J Pediatr 1988; 113: 345-353.

22. Hossain MM, Kawser CA, Amin R, Talukder MQR. Neonatal morbidity among infants born to diabetic mothers. Bangladesh J Child Health 1994; 15: 77-83.

23. Tsang RC, Chen IW, Fiedman MA. Parathyroid function in infants of diabetic mother.Journal of Peadiatrics 1975; 86: 399-404.

24. Aynsley- Green A, Soltesz G. Disorders of blood glucose homeostasis in the neonate. In: Roberton $\mathrm{N} R \mathrm{C}$, editor.Textbook of Neonatology. 2nd ed. London: Churchill Livingstone; 1992; 777-796.

25. Doeorari AK, Kabra SK, Paul VK, Singh M. Perinatal outcome of infants born to diabetic mothers.Indian Paediatr 1991; 28:1271-75.

26. Aynsley- Green A, Soltesz G. The infant of a diabetic mother. In: Roberton NRC, editor. A textbook of neonatology. 2nd ed. London: Churchill Livingestone, 1992: 333-7. 